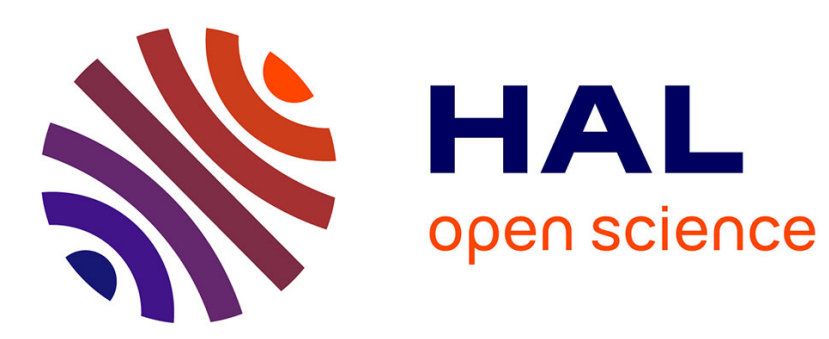

\title{
Is happiness different from flourishing? Cross-country evidence from the ESS
}

Andrew E. Clark, Claudia Senik

\section{To cite this version:}

Andrew E. Clark, Claudia Senik. Is happiness different from flourishing? Cross-country evidence from the ESS. 2011. halshs-00561867

\section{HAL Id: halshs-00561867 https://shs.hal.science/halshs-00561867}

Preprint submitted on 2 Feb 2011

HAL is a multi-disciplinary open access archive for the deposit and dissemination of scientific research documents, whether they are published or not. The documents may come from teaching and research institutions in France or abroad, or from public or private research centers.
L'archive ouverte pluridisciplinaire HAL, est destinée au dépôt et à la diffusion de documents scientifiques de niveau recherche, publiés ou non, émanant des établissements d'enseignement et de recherche français ou étrangers, des laboratoires publics ou privés. 


\section{PARIS SCHOQL OF ECONOMICS}

WORKING PAPER N²011 - 04

Is happiness different from flourishing?

Cross-country evidence from the ESS

Andrew E. Clark

Claudia Senik

JEL Codes: I31

Keywords: happiness, life satisfaction, eudaimonia, European Social Survey 


\title{
Is Happiness Different From Flourishing?
}

\section{Cross-Country Evidence from the ESS}

\author{
Andrew E. Clark (Paris School of Economics and IZA) \\ Claudia Senik (Paris School of Economics, Université Paris-Sorbonne)
}

\author{
January 2011
}

\begin{abstract}
This paper appeals to novel survey information on over 30000 individuals in 21 European countries to address an important and controversial question with respect to well-being: Do cognitive, hedonic and eudaimonic measures of well-being reflect very different aspects of individual quality of life? Or, more precisely, do the subjective appreciation of these dimensions by individuals exhibit different patterns? Our empirical results first reveal a very significant correlation between happiness and life satisfaction. Second, someone with high standard "hedonic" well-being (happiness or life satisfaction) is likely to have high eudaimonic well-being as well (flourishing, vitality, resilience and functioning). In addition, the factors that are correlated with the different measures of well-being seem to be very similar at the individual level. For example, marriage, higher income and greater education are associated with greater satisfaction, but also with higher levels of flourishing, vitality, resilience and functioning. This fit is not perfect, however, and men notably report lower levels of standard well-being measures, but higher eudaimonic well-being.
\end{abstract}

Keywords: Happiness, Life Satisfaction, Eudaimonia, European Social Survey.

JEL Codes: I31.

Address for Correspondence: Andrew Clark, PSE, 48 Boulevard Jourdan, 75014 Paris, FRANCE; Tel: +33-1-43-13-63-29; E-mail: Andrew.Clark@ens.fr.

* The Norwegian Social Science Data Services (NSD) is the data archive and distributor of the ESS data. We are very grateful to Marc Fleurbaey and two anonymous referees for constructive comments, and Conchita D'Ambrosio, Felicia Huppert and Nic Marks for useful discussions. We thank CEPREMAP for financial support. 


\section{Is Happiness Different From Flourishing?}

\section{Cross-Country Evidence from the ESS}

\section{Introduction}

There has been something of a sea-change in Economics over the past ten or fifteen years, with increasing attention being paid to measures of subjective well-being. This has come hand-in-hand with a considerable real debate about the way in which empirical analysis in social sciences should be carried out. In the context of well-being, one recurrent topic is measurement.

As a general rule, economists have relied on the single-item measures of happiness or satisfaction that are now commonly found in large-scale surveys such as the British Household Panel Survey, the German Socio-Economic Panel, and the International Social Survey Programme. It is probably fair to say that to date relatively little attention has been paid to this choice of what measure to use in the profession, ${ }^{1}$ beyond work that has attempted to show that these measures do indeed exhibit a certain amount of validity (some of which is surveyed in Clark et al., 2008). However, the question of which type of well-being is germane, and whether measures should be single- or multi-item has now become an area of debate and empirical exploration (e.g. Krueger and Schkade, 2008).

In this paper, we use a dataset that contains various different measures of well-being, collected from the same individuals. To date, the standard variables that are considered in the economics literature measure feelings of satisfaction or happiness, typically with life as a whole or with income. These are arguably mostly hedonic measures that are based on pleasure. One issue regarding these standard measures has been the difference between the cognitive aspect of well-being, i.e. the judgements one can make about one's life, and pure emotional hedonic pleasure, such as positive (or negative) affect. The first notion is likely to be elicited by the Life Satisfaction Question (which is considered to be partly cognitive),

1 Economists are much less likely to design their own survey instruments than are Sociologists and Psychologists. As such, we can use the standard get-out that "we can only use what is there". 
whereas the hedonic dimension is probably more present in the Happiness Question (see below). In the current paper, we will refer to both of these as standard hedonic measures (as in the Stanford Encyclopedia of Philosophy). Ongoing research is trying to disentangle these two dimensions, asking whether emotional feeling is just one element of the cognitive evaluation of individual life, or whether cognitive judgements themselves are part of the emotional feeling of happiness or life satisfaction. Another way to look at this is to consider the possibility that subjective well-being is just one element of utility, i.e. of preferences, alongside other arguments (see for instance the discussion in Loewenstein and Ubel, 2008, regarding utility, happiness and disability).

A second issue is whether all of what makes up the good life is based only on pleasure. Other measures of well-being have proposed the inclusion of additional non-pleasure aspects of individuals' lives, perhaps the most challenging of which is Amartya Sen's notion of capabilities and functionings. These latter reflect the set of potential and actual achievements that are available to an individual. One key question that can then be asked is the extent to which these measures overlap: is hedonic pleasure just one element of individual's functionings (Deci and Ryan, 2008, and Fleurbaey, 2009)? While these functionings are usually thought of as objective circumstances of the individual, some researchers have also sought to measure them via individuals' subjective appreciations. For example, Benjamin et al. (2010) underline the role of both the sense of purpose and control, as well as status and happiness considerations, that determine individual's behaviour in hypothetical choice experiments. In the current paper, we appeal to measures of eudaimonia to reflect this notion of functioning, where eudaimonia refers to the idea of flourishing or developing human potential. In practical terms, the eudaimonic well-being to which we refer is measured by survey questions on autonomy, determination, interest and engagement, aspirations and motivation, and a sense of meaning, direction or purpose in life. ${ }^{2}$

There are of course a number of ideas of what makes up the good life. One difficulty in taking this debate forwards empirically has been identifying datasets that include both

\footnotetext{
${ }^{2}$ In their seminal 2004 paper "Beyond Money: toward an economy of well-being”, Diener and Seligman called for: "a national well-being index [to] be created that systematically assesses key well-being variables for representative samples, including positive and negative emotions, engagement, purpose and meaning, optimism and trust, and life satisfaction, as well as satisfaction with specific domains of life.”
} 
hedonic and non pleasure-based measures of well-being. In the absence of empirical analysis, the supposed difference between well-being measures, or the superiority of one over the other, has been based on persuasive arguments rather than empirical analysis. In this paper we are able to appeal to novel data collected in Wave 3 of the European Social Survey, which contains both hedonic, cognitive and eudaimonic measures of well-being. As these were collected from the same sample of respondents, we can provide one of the first large-scale analyses of the similarities and differences between these well-being measures.

The remainder of the paper is organised as follows. Section 2 describes the data and our key variables and provides some initial bivariate correlations. Section 3 moves on to multivariate analysis and the final section concludes.

\section{Pleasure and Meaning in the European Social Survey}

The data we analyse here come from the European Social Survey (the ESS: freely available from http://www.europeansocialsurvey.org). The ESS is a multi-country survey which has covered 30 different countries at various points over its first three rounds. Wave 3 of the ESS, collected in 2006/2007, covers 25 different countries and contains a special module on well-being (see Huppert et al., 2009, and Clark and Senik, 2010). The original sample includes just over 47000 observations. We here drop four countries, in which the income variables were not readily usable because they were measured and coded differently, and restrict the sample to those of working age (16-65), producing an analysis sample size of just over 32000 individuals.

\section{Hedonic and cognitive measures}

To carry out the analysis proposed here, we require measures of hedonic, cognitive and eudaimonic well-being. The first is provided by the ESS question on happiness: respondents are asked "Taking all things together, how happy would you say you are?", with answers on a 0 to 10 scale, where 0 corresponds to "Extremely Unhappy" and 10 to "Extremely Happy". None of the other responses are labelled. Analogously, life satisfaction, which is a priori a more cognitive notion of well-being, is measured via the answer to the question "All things considered, how satisfied are you with your life as a whole nowadays?", with answers on a 0 
to 10 scale, where 0 means extremely dissatisfied and 10 means extremely satisfied.

The distribution of happiness and life satisfaction in our 21 countries in Wave 3 of the ESS is shown in Table 1. As is often the case with respect to well-being measures, the distribution of both of the variables in Table 1 is right-skewed. The mean and median happiness scores are 7 and 8 respectively, with analogous figures for life satisfaction of 7 and 7. The two measures appear similar to each other, and are relatively highly correlated, with a correlation coefficient of 0.60 . Self-declared happiness is somewhat higher than self-declared life satisfaction. A reasonably large numbers of respondents report low values of hedonic well-being, with 18 per cent having happiness scores of five or less, and 24 percent life satisfaction scores of five or less. In terms of their distribution, life satisfaction varies somewhat more than happiness across countries (as reflected in the $\chi^{2}$-statistics in the raw data). In what follows, we will refer to happiness and life satisfaction as hedonic measures of well-being. ${ }^{3}$

\section{Eudaimonic Measures}

There are many different subjective questions in the ESS, and the answers to them can be combined to produce a wide variety of measures of well-being. Our first eudaimonic measure here is that of flourishing, as described in Huppert and So (2009). This is based on the answers to seven different well-being questions. The first one of these is a happiness question: as our goal here is to see how hedonic and eudaimonic measures relate to each other, we therefore drop the happiness aspect of flourishing. Our modified version of Huppert and So's index is defined by the answers to the six different questions below.

Engagement, interest I love learning new things.

Meaning, purpose I generally feel that what I do in my life is valuable and worthwhile.

Self-esteem In general, I feel very positive about myself.

\footnotetext{
${ }^{3}$ Although a number of authors would argue that satisfaction scores are more evaluative, and hedonic measures should be restricted to feelings as opposed to judgments.
} 
Optimism

Resilience

Positive relationships
I'm always optimistic about my future.

When things go wrong in my life it generally takes me a long time to get back to normal. (reverse coding)

The first two of these are defined by Huppert and So as "core features", in that someone who is flourishing has to agree with these statements. The measure they propose of flourishing is thus agreement with the first two questions, plus agreement with at least three of the next four questions. Fifty six percent of the ESS sample is flourishing according to this definition. ${ }^{4}$

The second measure we appeal to is that developed by the New Economics Foundation (2008). ${ }^{5}$ Appendix 3 of this document describes how indices are created to measure Emotional Well-being, a Satisfying Life, Vitality, Resilience and Self-Esteem, Positive Functioning, Supportive Relationships, Trust and Belonging, and Well-Being at Work. The first two and last one of these are obviously hedonic in nature. For the purpose of comparing hedonic to eudaimonic well-being we have here retained the third through fifth items in this list: vitality, resilience and positive functioning. Each of these three is constructed as the unweighted sum of the answers to a number of z-score transformed questions (such that each of the questions has a mean of zero and a variance of one).

Vitality consists of answers to questions on how much of the time during the past week the individual felt tired, felt that everything they did was an effort, could not get going, had restless sleep, had a lot of energy, and felt rested when they woke up in the morning, plus the respondent's general health and whether their life involves a lot of physical activity. All of these are recoded so that higher values reflect greater vitality.

Similarly, resilience and self-esteem is given the sum of the answers to the four following

\footnotetext{
${ }^{4}$ Cronbach's alpha for the answers to the six measures we keep from Huppert and So's measure is 0.63.

${ }^{5}$ The New Economics Foundation (NEF) is an independent think-and-do tank that aims to improve quality of life by promoting innovative solutions that challenge mainstream thinking on economic, environmental and social issues: see http://www.neweconomics.org/.
} 
z-score transformed questions: "In general I feel very positive about myself", "At times I feel as if I am a failure", "I'm always optimistic about my future", and "When things go wrong in my life, it generally takes me a long time to get back to normal". Again, all of these are recoded so that higher numbers reflect greater resilience.

Last, positive functioning is determined by the answers to the following questions: "In my daily life I get very little chance to show how capable I am", "Most days I feel a sense of accomplishment from what I do", "In my daily life, I seldom have time to do the things I really enjoy", "I feel I am free to decide how to live my life", "How much of the time during the past week have you felt bored?", "How much of the time during the past week have you been absorbed in what you were doing", "To what extent do you get a chance to learn new things?", "To what extent do you feel that you get the recognition you deserve for what you do?", and "I generally feel that what I do in my life is valuable and worthwhile". ${ }^{6}$

\section{Bivariate Correlations}

The two hedonic measures, self-declared Happiness and Life Satisfaction, described above are both answered on 0 to 10 ordinal scales. The flourishing measure from Huppert and So is a binary variable, while the three New Economics Foundation measures are summed zscores. In the regression analysis we will keep these variables in their original formats, but to analyse the bivariate correlations we convert all of them to binary format. With respect to the hedonic measures, this is done by creating a dummy variable for reporting a score of 8 or more on the 0 to 10 scale (which is the case for 54 and 50 percent of the sample regarding happiness and life satisfaction respectively). As noted above, $56 \%$ of the ESS sample is flourishing according to Huppert and So's measure. Last, vitality, resilience and functioning are recoded into binary variables according to their respective median values, so that $50 \%$ of the sample has high values of these variables.

The bivariate correlations between hedonic and eudaimonic variables are presented in Table 2. These correlation coefficients are all between 0.25 and 0.30 , and are all significant at better than the $0.01 \%$ level. Note that there is no issue of sample comparability here, as both hedonic and eudaimonic measures are supplied by the same individuals. The right-hand side

\footnotetext{
${ }^{6}$ The Cronbach's alpha scores for the sets of questions that are used to make up vitality, resilience and positive functioning are $0.70,0.61$ and 0.65 respectively.
} 
of this table shows the correlations between our three different eudaimonic measures. These are all mostly around 0.3 as well, except that between resilience and flourishing which is higher at 0.5 , suggesting that these three measures are not capturing exactly the same phenomenon.

Another intuitive way of looking at the question of the correlation between different wellbeing measures is to ask whether someone who is deprived hedonically is also more likely to be deprived eudaimonically. The results here are presented in Table 3. As in Table 2, there seems to be a reasonably strong relationship between hedonic and eudaimonic measures of well-being, in the sense that someone who lacks one is very likely to lack the other as well. This is consistent with some of the results in White and Dolan (2009), who examine both hedonic and eudaimonic measures of well-being using Day Reconstruction Method (DRM) techniques. As their Figure 1 shows, many of the activities that are considered to be pleasurable are also evaluated as being eudaimonically rewarding. However, the fit is by no means perfect and some activities (for example, eating and watching TV) are pleasurable but not rewarding, while others (such as work and housework) are rewarding but not pleasurable. Finally, the numbers in Table 3 also underline the similarity between life satisfaction and happiness.

\section{Well-Being Regressions}

A second simple way of evaluating the difference, if any, between hedonic and eudaimonic measures of well-being is to carry out a regression analysis using "standard" socio-demographic variables as controls. ${ }^{7}$ The results are shown in Table 4 . Columns 1 and 2 of Table 4 are estimated via an ordered probit, and column 3 via a probit (there are therefore no corresponding $\mathrm{R}^{2}$ values here); the remaining three columns are estimated via OLS.

Let us underline again the great similarity in the structure of Life Satisfaction and Happiness, with the exception of house-workers who are more happy than satisfied with their life (as compared with employed people).

\footnotetext{
${ }^{7}$ There are some similarities here to the work of Oswald and $\mathrm{Wu}$ (2010), who compare the distribution of subjective and objective outcomes across American States.
} 
There are two levels at which the comparison between the regression results in Table 4 can be carried out: individual-level variables, such as age, sex and education, and the country fixed effects. There are 17 individual socio-demographic variables in Table 4, and the perhaps surprising conclusion is that the patterns of hedonic and eudaimonic regressions are similar for the great majority of them. An opposition between the results is found for only four variables. Most significantly, the first column shows that men have consistently lower hedonic well-being scores (see Nolen-Hoeksema and Rusting, 1999), but report significantly higher levels of eudaimonia, such as vitality and resilience. The second sharp difference is found for the retired, who consistently report lower levels of eudaimonic well-being, but are not significantly different from non-retirees in hedonic terms. The other two variables for which there is some disagreement between the six columns of Table 4 are the labour-force status variables of Full-Time education and (to a certain extent) looking after the house and children: both of these groups do relatively well hedonically, but do not have higher eudaimonia scores.

It thus turns out that in spite of the vivid debates about the correct notion of well-being, the subjective appreciation of life satisfaction, happiness and eudaimonia are similar to each other, and are characterized by very similar socio-demographic patterns (for example, the richer and the higher-educated are both more happy, more satisfied and have higher eudaimonia scores) ${ }^{8}$

However, the same is not true for groups of countries. For example, just considering life satisfaction and flourishing, the estimated country dummies are oppositely signed, and both significant, for Belgium, Bulgaria and Portugal. Further the significant life satisfaction effect is not reflected in any flourishing effect for the United Kingdom, Latvia, the Netherlands, Norway, Poland and Slovenia. Considering the separate eudaimonic domains of Vitality, Resilience and Functioning reveals a number of other differences between countries. In fact, only very few countries attract consistent estimated coefficients across the six columns in Table 4: all else equal, living in Austria is associated with significantly higher scores in all the

\footnotetext{
${ }^{8}$ It is worth underlining that the discussion here is couched in terms of average patterns in the data. Ths similarity between the two measures may be lesser if we want to identify the worst-off in the population, for example. In general, the distribution of individual well-being as captured by different measures seems like a useful topic for further research.
} 
well-being dimensions, whereas the opposite is true of France, Latvia, Russia and Slovakia. It is intriguing that the group of countries whose inhabitants are always found to score higher in terms of subjective happiness and satisfaction, i.e. Scandinavian countries (Denmark, Norway Sweden), Ireland and Switzerland (see Senik, 2010) actually attract higher scores in all hedonic and eudaimonic dimensions except resilience, where the effect is negative.

One way of formalising the above statements is to look at indices of similarity between the estimated sets of coefficients in the different columns of Table 4. This correlation can be calculated both cardinally, using Pearson correlations, and ordinally, using Spearman correlations. The results are shown in Table 5. Both sets of correlation coefficients tell the same story here. First, happiness and life satisfaction produce extremely similar data shapes. Whatever the cognitive component of satisfaction that is not present in happiness, it appears to make remarkably little difference to the shapes found in the ESS data. Second, the correlation between the hedonic measures and the eudaimonic measures, in terms of how they fit the observable explanatory variables in Table 4, is reasonably high. There is, however, one exception, with respect to resilience. This concept does not seem to be particularly closely related to either happiness or satisfaction, which is perhaps a finding that is worthy of future investigation. $^{9}$

To further analyse any divergences between hedonic and eudaimonic well-being, Table 6 presents the results from a series of probit estimations. The dependent variable in the four columns is a dummy variable for an individual reporting high eudaimonic well-being, as defined by the measures of flourishing, vitality, resilience and functioning respectively (in the binary sense used in Tables 2 and 3) but having low life satisfaction (i.e. a score of 7 or less on the 0 to 10 scale). The actual results are qualitatively very similar across these four columns.

The results in the first four columns show that those who are dissatisfied but who enjoy

\footnotetext{
${ }^{9}$ We can carry out the same analysis as in Table 5 but limiting our attention uniquely to the estimated coefficients on the country dummies. Life satisfaction and happiness continue to produce almost exactly the same data shapes. However, the similarity between eudaimonic and hedonic measures of well-being is systematically lower. This means the demographic patterns of the correlates of eudaimonic and hedonic wellbeing (in terms of age, sex, education and so on) are much more similar than are the country correlates of the same.
} 
eudaimonic well-being are more likely to be men than women, and are more likely to be in their mid-age (around the mid-forties). This probability is also higher for the educated, the single and the separated. Perhaps surprisingly, income plays only a very minor role in distinguishing hedonic and eudaimonic well-being (in particular, it is not the case that the relatively better-off are happy but have less meaningful lives). With respect to labour-force status, both the sick and disabled and the retired are significantly less likely to report low life satisfaction and high levels of eudaimonia.

The country dummies in Table 6 are for the most part very significant. These show that dissatisfying but "meaningful" lives are the least likely in the Nordic countries, and Switzerland, the Netherlands and Belgium; they are the most common in Bulgaria and Portugal (as compared to Germany, the omitted country). Any attempt at explaining this pattern must remain for the moment tentative. It is worth remembering that a number of potential individual-level variables, such as education, labour-force status and income, have been controlled for in this regression. Candidate explanations should therefore rely on other individual-level variables (such as religion for example), or aggregate variables which reflect cultural differences across countries.

It is also possible to re-run all of the analysis in Table 6 for the mirror phenomenon of being satisfied but having lower levels of flourishing, vitality etc. This produces estimated coefficients that are very often oppositely signed to those in Table 6. As these do not add anything particular to the analysis, we have not presented them here (they are available on request).

\section{Conclusion}

This paper has appealed to novel survey information on over 30000 individuals in 21 European countries to address an important and controversial question with respect to wellbeing: Do cognitive, hedonic and eudaimonic measures of well-being reflect very different aspects of individual quality of life, as some people have suggested? Or, more precisely, does the subjective appreciation of these dimensions by individuals follow different patterns?

Our empirical results first reveal a very significant correlation between the measures of happiness and life satisfaction. Second, someone with high "hedonic" well-being (happiness 
or life satisfaction) is likely to have high eudaimonic well-being as well (flourishing, vitality, resilience and functioning). In addition, the factors that are correlated with the different measures of well-being seem to be very similar at the individual level. For example, marriage, higher income and greater education are associated with greater satisfaction, but also with higher levels of flourishing, vitality, resilience and functioning. This fit is not perfect, however, and men notably report lower levels of hedonic well-being but higher eudaimonic well-being. This opposition is even stronger at the country level. One first conclusion to be drawn then is that the two types of well-being measures seem to be more similar within countries than they are across countries. Once again, cross-country comparisons would seem to be fraught with danger.

Although the different well-being measures are correlated, the match is by no means complete. As such, many individuals are happy, but have low eudaimonic well-being, while others have meaningful lives but are not satisfied or happy. Our last set of regression results have shown that these phenomena are systematically correlated with a number of individual characteristics (although not with money) and especially with country dummies. The overall conclusion then is that there definitely seems to be a certain amount of overlap between the different subjective well-being measures. However, those who have argued that "happiness is not everything" do seem to have a point. Higher levels of happiness or life satisfaction do increase the likelihood of having a more flourishing life, but by no means guarantee it.

We have here only started to scratch the surface of what can be done with the various well-being questions available in the ESS. Many important questions have not been answered. It would be of great interest to create some kind of multidimensional poverty index, based on subjective deprivation, defined over the different aspects of well-being. ${ }^{10}$ We have not addressed the questions of which measure of well-being is the best or more relevant for public guidance. There are many ways of doing so, which take into account the variety of measures available. Decancq et al. (2009) use subjective information to correct for the frame of reference and the different values that individuals may put on different outcomes. By doing so, they attempt to compare underlying levels of welfare between individuals. An additional

\footnotetext{
${ }^{10}$ With respect to quantitative variables, this is discussed in Bourguignon and Chakravarty (2003); the case of qualitative variables is discussed in Alkire and Foster (2011) and Bossert et al. (2009).
} 
way of making progress in this direction might be to appeal to panel data to show which wellbeing measures are the strongest predictors of individual future behaviours (such as moving house, quitting one's job, or getting divorced). It would also be possible to look at individual morbidity and mortality outcomes along the same lines. The ESS is unfortunately not panel, and so cannot be used in this way. It has however introduced a much broader menu of wellbeing questions than is typically found in social science surveys, and the inclusion of some of these in existing panel surveys would arguably be an important step forward in broadening our understanding of what constitutes a good life at the individual level. 
Table 1. Life Satisfaction and Happiness in Wave 3 of the European Social Survey

\begin{tabular}{|c|c|c|c|c|c|c|c|}
\hline How happy are you? & Frequency & Percent & $\begin{array}{l}\text { Cumulative } \\
\text { Percentage }\end{array}$ & $\begin{array}{c}\text { Life satisfaction as a } \\
\text { whole }\end{array}$ & Frequency & Percent & $\begin{array}{l}\text { Cumulative } \\
\text { Percentage }\end{array}$ \\
\hline Extremely unhappy & 147 & 0 & 0 & Extremely dissatisfied & 477 & 2 & 2 \\
\hline 1 & 183 & 1 & 1 & 1 & 380 & 1 & 3 \\
\hline 2 & 367 & 1 & 2 & 2 & 648 & 2 & 5 \\
\hline 3 & 688 & 2 & 4 & 3 & 1082 & 3 & 8 \\
\hline 4 & 853 & 3 & 7 & 4 & 1236 & 4 & 12 \\
\hline 5 & 2921 & 9 & 17 & 5 & 3355 & 11 & 23 \\
\hline 6 & 2566 & 8 & 25 & 6 & 2682 & 9 & 32 \\
\hline 7 & 5944 & 19 & 44 & 7 & 5392 & 17 & 49 \\
\hline 8 & 8966 & 29 & 72 & 8 & 8144 & 26 & 75 \\
\hline 9 & 5427 & 17 & 90 & 9 & 4783 & 15 & 90 \\
\hline Extremely happy & 3161 & 10 & 100 & Extremely satisfied & 3116 & 10 & 100 \\
\hline Total & 31222 & & & Total & 31294 & & \\
\hline
\end{tabular}

Note: Weighted statistics. Sample: Aged between 16 and 65.

Table 2. Pairwise correlations between Hedonic and Eudaimonic Measures of Well-Being

\begin{tabular}{lcccccc}
\hline & Happiness & Life Satisfaction & Flourishing & Vitality & Resilience & Functioning \\
\hline Happiness & 1 & & & & & \\
Life Satisfaction & 0.6106 & 1 & & & & \\
Flourishing & 0.2718 & 0.2629 & 1 & & & \\
Vitality & 0.2573 & 0.2574 & 0.2752 & 1 & 1 & \\
Resilience & 0.2635 & 0.2608 & 0.4967 & 0.3207 & 0.3105 & 1 \\
Functioning & 0.2866 & 0.2987 & 0.3126 & 0.3084 & & \\
\hline
\end{tabular}

Table 3. Eudaimonia scores, by levels of Hedonic Well-Being

\begin{tabular}{lcccc}
\hline & Flourishing & Vitality & Resilience & Functioning \\
\hline High Life Satisfaction & 69.2 & 62.7 & 62.7 & 64.8 \\
Low Life Satisfaction & 43.1 & 37.0 & 36.7 & 34.9 \\
High Happiness & 68.5 & 61.7 & 61.8 & 62.9 \\
Low Happiness & 41.4 & 35.8 & 35.3 & 34.1 \\
All & 56.2 & 50.0 & 49.7 & 50.0 \\
\end{tabular}


Table 4. Hedonic and Eudaimonic Well-Being Regressions

\begin{tabular}{|c|c|c|c|c|c|c|}
\hline & Life Satisfaction & Happiness & Flourishing & Vitality & Resilience & Functioning \\
\hline \multirow[t]{2}{*}{ Male } & $-0.052^{* *}$ & $-0.074 * *$ & $0.090^{* *}$ & $0.946^{* *}$ & $0.582^{* *}$ & 0.021 \\
\hline & $(0.014)$ & $(0.014)$ & $(0.018)$ & $(0.060)$ & $(0.036)$ & $(0.052)$ \\
\hline \multirow[t]{2}{*}{ Age } & $-0.051 * *$ & $-0.056^{* *}$ & -0.005 & $-0.116^{* *}$ & $-0.105^{* *}$ & $-0.054^{* *}$ \\
\hline & $(0.004)$ & $(0.004)$ & $(0.005)$ & $(0.018)$ & $(0.010)$ & $(0.015)$ \\
\hline \multirow[t]{2}{*}{ Age-squared/1000 } & $0.539^{* *}$ & $0.565^{* *}$ & -0.014 & $1.325^{* *}$ & $1.125^{* *}$ & $1.070^{* *}$ \\
\hline & $(0.047)$ & $(0.047)$ & $(0.059)$ & $(0.205)$ & $(0.121)$ & $(0.178)$ \\
\hline \multirow[t]{2}{*}{ Secondary Education } & $0.047^{* *}$ & 0.025 & $0.149^{* *}$ & $0.349^{* *}$ & $0.328^{* *}$ & $0.487^{* *}$ \\
\hline & $(0.017)$ & $(0.017)$ & $(0.022)$ & $(0.076)$ & $(0.045)$ & $(0.066)$ \\
\hline \multirow[t]{2}{*}{ Tertiary Education } & $0.090^{* *}$ & $0.069 * *$ & $0.243^{* * *}$ & $0.408^{* *}$ & $0.357^{* *}$ & $0.946 * *$ \\
\hline & $(0.020)$ & $(0.020)$ & $(0.025)$ & $(0.085)$ & $(0.050)$ & $(0.074)$ \\
\hline \multirow[t]{2}{*}{ Separated } & $-0.267^{* *}$ & $-0.339 * *$ & $-0.085^{* *}$ & $-0.471 * *$ & $-0.177 * *$ & $-0.284 * *$ \\
\hline & $(0.022)$ & $(0.022)$ & $(0.028)$ & $(0.096)$ & $(0.056)$ & $(0.083)$ \\
\hline Widowed & $-0.310^{* *}$ & $-0.492 * *$ & $-0.127^{*}$ & $-1.699 * *$ & $-0.385 * *$ & -0.266 \\
\hline & $(0.039)$ & $(0.039)$ & $(0.050)$ & $(0.173)$ & $(0.101)$ & $(0.152)$ \\
\hline Never in Couple & $-0.200 * *$ & $-0.322 * *$ & $-0.129 * *$ & $-0.271 * *$ & $-0.337 * *$ & $-0.259^{* *}$ \\
\hline & $(0.019)$ & $(0.019)$ & $(0.025)$ & $(0.084)$ & $(0.050)$ & $(0.073)$ \\
\hline Log Income & $0.201 * *$ & $0.164 * *$ & $0.116^{* *}$ & $0.545^{* *}$ & $0.437 * *$ & $0.517 * *$ \\
\hline & $(0.009)$ & $(0.009)$ & $(0.012)$ & $(0.040)$ & $(0.024)$ & $(0.035)$ \\
\hline FT Education & $0.093 * *$ & $0.079 * *$ & -0.019 & -0.232 & -0.121 & 0.197 \\
\hline & $(0.028)$ & $(0.028)$ & $(0.035)$ & $(0.121)$ & $(0.071)$ & $(0.104)$ \\
\hline Active Unemployed & $-0.429 * *$ & $-0.273^{* *}$ & $-0.293 * *$ & $-0.847 * *$ & $-0.518^{* *}$ & $-1.531^{* *}$ \\
\hline & $(0.034)$ & $(0.034)$ & $(0.043)$ & $(0.150)$ & $(0.088)$ & $(0.131)$ \\
\hline Inactive Unemployed & $-0.366 * *$ & $-0.295^{* *}$ & $-0.427 * *$ & $-1.535^{* *}$ & $-0.801 * *$ & $-1.400^{* *}$ \\
\hline & $(0.043)$ & $(0.043)$ & $(0.057)$ & $(0.191)$ & $(0.113)$ & $(0.168)$ \\
\hline Sick or Disabled & $-0.473 * *$ & $-0.376^{* *}$ & $-0.470 * *$ & $-5.745^{* *}$ & $-1.542 * *$ & $-2.043 * *$ \\
\hline & $(0.038)$ & $(0.038)$ & $(0.049)$ & $(0.166)$ & $(0.097)$ & $(0.146)$ \\
\hline Retired & 0.030 & -0.007 & $-0.125^{* *}$ & $-1.000 * *$ & $-0.156^{*}$ & -0.156 \\
\hline & $(0.028)$ & $(0.029)$ & $(0.036)$ & $(0.125)$ & $(0.074)$ & $(0.109)$ \\
\hline Community or Military Service & 0.145 & 0.019 & -0.068 & 0.473 & 0.282 & -0.052 \\
\hline & $(0.154)$ & $(0.155)$ & $(0.196)$ & $(0.670)$ & $(0.406)$ & $(0.595)$ \\
\hline Housework, looking after children, others & 0.028 & $0.040^{*}$ & 0.003 & -0.079 & -0.055 & -0.052 \\
\hline & $(0.017)$ & $(0.017)$ & $(0.022)$ & $(0.076)$ & $(0.045)$ & $(0.066)$ \\
\hline Other & 0.022 & 0.047 & 0.100 & -0.336 & 0.063 & 0.018 \\
\hline & $(0.050)$ & $(0.051)$ & $(0.064)$ & $(0.219)$ & $(0.130)$ & $(0.192)$ \\
\hline Austria & $0.462^{* *}$ & $0.213^{* *}$ & $0.172^{* *}$ & $1.442^{* *}$ & 0.077 & $1.250^{* *}$ \\
\hline & $(0.039)$ & $(0.039)$ & $(0.050)$ & $(0.173)$ & $(0.102)$ & $(0.150)$ \\
\hline Belgium & $0.287 * *$ & $0.265^{* *}$ & $-0.164^{* *}$ & -0.148 & $-1.032 * *$ & 0.142 \\
\hline & $(0.038)$ & $(0.038)$ & $(0.048)$ & $(0.165)$ & $(0.098)$ & $(0.142)$ \\
\hline Bulgaria & $-0.404 * *$ & $-0.468^{* *}$ & $0.134^{*}$ & $0.848^{* *}$ & $0.280^{*}$ & $0.683^{* *}$ \\
\hline & $(0.048)$ & $(0.048)$ & $(0.062)$ & $(0.216)$ & $(0.126)$ & $(0.186)$ \\
\hline Switzerland & $0.555^{* *}$ & $0.486^{* *}$ & $0.259^{* *}$ & $0.903^{* *}$ & $-0.200^{*}$ & $1.032^{* *}$ \\
\hline & $(0.040)$ & $(0.040)$ & $(0.051)$ & $(0.171)$ & $(0.102)$ & $(0.148)$ \\
\hline Denmark & $0.901 * *$ & $0.681 * *$ & $0.251^{* *}$ & 0.086 & -0.198 & $2.299 * *$ \\
\hline & $(0.041)$ & $(0.041)$ & $(0.051)$ & $(0.174)$ & $(0.103)$ & $(0.150)$ \\
\hline Spain & $0.452^{* *}$ & $0.413^{* *}$ & $0.166^{* *}$ & -0.334 & 0.018 & $-1.343^{* *}$ \\
\hline & $(0.043)$ & $(0.043)$ & $(0.054)$ & $(0.185)$ & $(0.110)$ & $(0.161)$ \\
\hline Finland & $0.590^{* *}$ & $0.528^{* *}$ & $0.130^{* *}$ & 0.154 & $-1.287^{* *}$ & 0.175 \\
\hline & $(0.038)$ & $(0.038)$ & $(0.047)$ & $(0.163)$ & $(0.096)$ & $(0.140)$ \\
\hline France & $-0.149^{* *}$ & 0.044 & $-0.256^{* *}$ & $-0.346^{*}$ & $-0.978 * *$ & $-0.928^{* *}$ \\
\hline & $(0.037)$ & $(0.037)$ & $(0.047)$ & $(0.162)$ & $(0.096)$ & $(0.140)$ \\
\hline United Kingdom & $0.136^{* *}$ & $0.152 * *$ & -0.025 & $-1.275^{* *}$ & $-0.990 * *$ & $-1.027^{* *}$ \\
\hline & $(0.037)$ & $(0.037)$ & $(0.047)$ & $(0.162)$ & $(0.096)$ & $(0.140)$ \\
\hline Ireland & $0.304 * *$ & $0.287^{* *}$ & $0.262^{* *}$ & 0.318 & $-0.355^{* *}$ & $0.512 * *$ \\
\hline & $(0.041)$ & $(0.041)$ & $(0.052)$ & $(0.179)$ & $(0.105)$ & $(0.155)$ \\
\hline Latvia & $-0.094 *$ & $-0.183 * *$ & -0.080 & -0.017 & $-0.910 * *$ & $-1.295^{* *}$ \\
\hline & $(0.040)$ & $(0.040)$ & $(0.051)$ & $(0.177)$ & $(0.104)$ & $(0.154)$ \\
\hline Netherlands & $0.372^{* *}$ & $0.294 * *$ & -0.007 & $0.441^{* *}$ & $-0.608 * *$ & $0.702 * *$ \\
\hline & $(0.038)$ & $(0.038)$ & $(0.047)$ & $(0.163)$ & $(0.096)$ & $(0.141)$ \\
\hline Norway & $0.362^{* *}$ & $0.361 * *$ & 0.079 & $0.493^{* *}$ & $-0.986^{* *}$ & $0.325^{*}$ \\
\hline & $(0.037)$ & $(0.037)$ & $(0.047)$ & $(0.161)$ & $(0.096)$ & $(0.139)$ \\
\hline Poland & $0.250^{* *}$ & $0.148^{* *}$ & -0.012 & $0.360^{*}$ & -0.143 & $0.459 * *$ \\
\hline & $(0.041)$ & $(0.041)$ & $(0.052)$ & $(0.180)$ & $(0.106)$ & $(0.157)$ \\
\hline Portugal & $-0.435 * *$ & $-0.224 * *$ & $0.279^{* *}$ & $-1.778 * *$ & -0.095 & $-0.963^{* *}$ \\
\hline & $(0.044)$ & $(0.045)$ & $(0.056)$ & $(0.194)$ & $(0.115)$ & $(0.168)$ \\
\hline Russia & $-0.286^{* *}$ & $-0.225^{* *}$ & $-0.301 * *$ & -0.030 & $-0.210^{*}$ & 0.082 \\
\hline & $(0.041)$ & $(0.041)$ & $(0.053)$ & $(0.183)$ & $(0.107)$ & $(0.160)$ \\
\hline Sweden & $0.536^{* *}$ & $0.460^{* *}$ & $0.110^{*}$ & -0.019 & $-0.684^{* *}$ & -0.193 \\
\hline & $(0.037)$ & $(0.037)$ & $(0.047)$ & $(0.160)$ & $(0.095)$ & $(0.139)$ \\
\hline Slovenia & $0.243^{* *}$ & $0.203^{* *}$ & 0.099 & $0.668^{* *}$ & -0.138 & $-0.315^{*}$ \\
\hline & $(0.042)$ & $(0.042)$ & $(0.053)$ & $(0.184)$ & $(0.109)$ & $(0.159)$ \\
\hline Slovakia & $-0.117 * *$ & $-0.135^{* *}$ & $-0.121^{*}$ & $-0.717 * *$ & $-1.322 * *$ & $-0.420^{*}$ \\
\hline & $(0.044)$ & $(0.044)$ & $(0.055)$ & $(0.193)$ & $(0.114)$ & $(0.166)$ \\
\hline Constant & & & $-0.562 * *$ & $-1.911 * *$ & $-0.788 * *$ & $-3.665^{* *}$ \\
\hline & & & $(0.146)$ & $(0.504)$ & $(0.297)$ & $(0.437)$ \\
\hline Observations & 24297 & 24247 & 23773 & 23694 & 23917 & 23317 \\
\hline Log-Likelihood & -47346.81 & -44715.03 & -15496.34 & -68824.05 & -56948.91 & -64182.61 \\
\hline Log-Likelihood at zero & -50460.01 & -47167.79 & -16299.51 & -70480.96 & -58139.32 & -65784.43 \\
\hline $\mathrm{R}$-squared & & & & 0.131 & 0.095 & 0.128 \\
\hline
\end{tabular}

Note: The omitted categories are: primary education, married, employed and Germany. Standard errors in parentheses.

* significant at $5 \%$; ** significant at $1 \%$ 
Table 5. The Correlation Between the Estimated Coefficients in Table 4

\begin{tabular}{|c|c|c|c|c|c|}
\hline & Life Satisfaction & Happiness & Flourishing & Vitality & Resilience \\
\hline \multirow[t]{2}{*}{ Happiness } & 0.961 & & & & \\
\hline & {$[0.957]$} & & & & \\
\hline \multirow[t]{2}{*}{ Flourishing } & 0.585 & 0.545 & & & \\
\hline & {$[0.533]$} & [0.539] & & & \\
\hline \multirow[t]{2}{*}{ Vitality } & 0.545 & 0.483 & 0.579 & & \\
\hline & {$[0.592]$} & {$[0.506]$} & {$[0.523]$} & & \\
\hline \multirow[t]{2}{*}{ Resilience } & 0.133 & 0.091 & 0.457 & 0.553 & \\
\hline & {$[0.094]$} & {$[0.040]$} & {$[0.483]$} & [0.499] & \\
\hline \multirow[t]{2}{*}{ Functioning } & 0.641 & 0.536 & 0.614 & 0.686 & 0.491 \\
\hline & {$[0.610]$} & {$[0.540]$} & {$[0.556]$} & {$[0.763]$} & {$[0.443]$} \\
\hline
\end{tabular}

Note: The first figure in each cell refers to the Pearson correlation coefficient; the figure underneath it in square brackets refers to the Spearman correlation coefficient. 
$\underline{\text { Table 6. Flourishing but Not Satisfied }}$

\begin{tabular}{|c|c|c|c|c|}
\hline & \multicolumn{4}{|c|}{ Low life satisfaction but high: } \\
\hline & Flourishing & Vitality & Resilience & Functioning \\
\hline \multirow[t]{2}{*}{ Male } & $0.082^{* *}$ & $0.202^{* *}$ & $0.195^{* *}$ & $0.053^{* *}$ \\
\hline & $(0.020)$ & $(0.020)$ & $(0.021)$ & $(0.020)$ \\
\hline \multirow[t]{2}{*}{ Age } & $0.035^{* *}$ & $0.019^{* *}$ & $0.014 *$ & $0.026^{* *}$ \\
\hline & $(0.006)$ & $(0.006)$ & $(0.006)$ & $(0.006)$ \\
\hline \multirow[t]{2}{*}{ Age-squared/1000 } & $-0.394 * *$ & $-0.216^{* *}$ & -0.136 & $-0.199 * *$ \\
\hline & $(0.067)$ & $(0.070)$ & $(0.071)$ & $(0.070)$ \\
\hline \multirow[t]{2}{*}{ Secondary Education } & $0.086^{* *}$ & 0.046 & $0.088 * *$ & $0.069^{* *}$ \\
\hline & $(0.025)$ & $(0.025)$ & $(0.026)$ & $(0.026)$ \\
\hline \multirow[t]{2}{*}{ Tertiary Education } & $0.078^{* *}$ & -0.030 & 0.023 & $0.107 * *$ \\
\hline & $(0.028)$ & $(0.029)$ & $(0.029)$ & $(0.029)$ \\
\hline \multirow[t]{2}{*}{ Separated } & $0.094 * *$ & $0.071 *$ & $0.073 *$ & $0.124 * *$ \\
\hline & $(0.031)$ & $(0.032)$ & $(0.032)$ & $(0.031)$ \\
\hline Widowed & 0.016 & $-0.138^{*}$ & 0.009 & $0.105^{*}$ \\
\hline & $(0.055)$ & $(0.060)$ & $(0.057)$ & $(0.053)$ \\
\hline Never in Couple & $0.077^{* *}$ & $0.126^{* *}$ & 0.047 & $0.119^{* *}$ \\
\hline & $(0.027)$ & $(0.028)$ & $(0.029)$ & $(0.029)$ \\
\hline Log Income & -0.021 & $-0.038^{* *}$ & 0.015 & -0.011 \\
\hline & $(0.013)$ & $(0.014)$ & $(0.014)$ & $(0.014)$ \\
\hline FT Education & -0.042 & $-0.127^{* *}$ & -0.064 & -0.077 \\
\hline & $(0.040)$ & $(0.041)$ & $(0.042)$ & $(0.044)$ \\
\hline Active Unemployed & -0.059 & 0.004 & 0.000 & $-0.165^{* *}$ \\
\hline & $(0.047)$ & $(0.048)$ & $(0.049)$ & $(0.052)$ \\
\hline Inactive Unemployed & $-0.177^{* *}$ & -0.087 & $-0.129^{*}$ & -0.092 \\
\hline & $(0.063)$ & $(0.063)$ & $(0.065)$ & $(0.064)$ \\
\hline Sick or Disabled & $-0.144 * *$ & $-0.681 * *$ & $-0.187 * *$ & -0.072 \\
\hline & $(0.055)$ & $(0.074)$ & $(0.059)$ & $(0.055)$ \\
\hline Retired & $-0.124 * *$ & $-0.105^{*}$ & $-0.102 *$ & -0.056 \\
\hline & $(0.041)$ & $(0.043)$ & $(0.043)$ & $(0.041)$ \\
\hline Community or Military Service & -0.008 & -0.013 & 0.140 & -0.490 \\
\hline & $(0.223)$ & $(0.219)$ & $(0.220)$ & $(0.304)$ \\
\hline Housework, looking after children, others & -0.031 & -0.047 & -0.035 & -0.010 \\
\hline & $(0.025)$ & $(0.026)$ & $(0.026)$ & $(0.026)$ \\
\hline Other & 0.128 & -0.141 & 0.037 & -0.133 \\
\hline & $(0.070)$ & $(0.077)$ & $(0.075)$ & $(0.079)$ \\
\hline Austria & $-0.306^{* *}$ & $-0.120^{*}$ & $-0.424 * *$ & $-0.233^{* *}$ \\
\hline & $(0.055)$ & $(0.055)$ & $(0.056)$ & $(0.057)$ \\
\hline Belgium & $-0.385 * *$ & $-0.279 * *$ & $-0.513 * *$ & $-0.207 * *$ \\
\hline & $(0.054)$ & $(0.056)$ & $(0.056)$ & $(0.054)$ \\
\hline Bulgaria & $0.234 * *$ & $0.163^{*}$ & $0.212 * *$ & $0.286^{* *}$ \\
\hline & $(0.063)$ & $(0.065)$ & $(0.064)$ & $(0.064)$ \\
\hline Switzerland & $-0.506^{* *}$ & $-0.325 * *$ & $-0.680^{* *}$ & $-0.370^{* *}$ \\
\hline & $(0.058)$ & $(0.059)$ & $(0.060)$ & $(0.058)$ \\
\hline Denmark & $-0.731 * *$ & $-0.711 * *$ & $-1.025^{* *}$ & $-0.606 * *$ \\
\hline & $(0.064)$ & $(0.069)$ & $(0.071)$ & $(0.064)$ \\
\hline Spain & $-0.214^{* *}$ & $-0.349 * *$ & $-0.336^{* *}$ & $-0.670^{* *}$ \\
\hline & $(0.059)$ & $(0.064)$ & $(0.060)$ & $(0.072)$ \\
\hline Finland & $-0.660^{* *}$ & $-0.706^{* *}$ & $-1.154 * *$ & $-0.688 * *$ \\
\hline & $(0.057)$ & $(0.062)$ & $(0.070)$ & $(0.061)$ \\
\hline France & -0.084 & 0.099 & $-0.180^{* *}$ & -0.101 \\
\hline & $(0.050)$ & $(0.051)$ & $(0.051)$ & $(0.052)$ \\
\hline United Kingdom & $-0.174 * *$ & $-0.324 * *$ & $-0.370 * *$ & $-0.371 * *$ \\
\hline & $(0.051)$ & $(0.055)$ & $(0.052)$ & $(0.055)$ \\
\hline Ireland & -0.104 & $-0.227 * *$ & $-0.325 * *$ & $-0.209 * *$ \\
\hline & $(0.055)$ & $(0.059)$ & $(0.057)$ & $(0.058)$ \\
\hline Latvia & -0.007 & 0.004 & $-0.315^{* *}$ & $-0.306^{* *}$ \\
\hline & $(0.053)$ & $(0.055)$ & $(0.056)$ & $(0.059)$ \\
\hline Netherlands & $-0.387 * *$ & $-0.187 * *$ & $-0.444 * *$ & $-0.230^{* *}$ \\
\hline & $(0.053)$ & $(0.054)$ & $(0.054)$ & $(0.054)$ \\
\hline Norway & $-0.366^{* *}$ & $-0.291^{* *}$ & $-0.668^{* *}$ & $-0.294 * *$ \\
\hline & $(0.052)$ & $(0.055)$ & $(0.056)$ & $(0.054)$ \\
\hline Poland & $-0.162^{* *}$ & -0.020 & $-0.134^{*}$ & -0.040 \\
\hline & $(0.056)$ & $(0.057)$ & $(0.056)$ & $(0.058)$ \\
\hline Portugal & $0.543^{* *}$ & -0.092 & $0.339 * *$ & 0.050 \\
\hline & $(0.057)$ & $(0.063)$ & $(0.057)$ & $(0.061)$ \\
\hline Russia & $-0.139 *$ & 0.051 & -0.001 & 0.000 \\
\hline & $(0.056)$ & $(0.057)$ & $(0.056)$ & $(0.057)$ \\
\hline Sweden & $-0.434 * *$ & $-0.448 * *$ & $-0.782 * *$ & $-0.458 * *$ \\
\hline & $(0.053)$ & $(0.056)$ & $(0.058)$ & $(0.055)$ \\
\hline Slovenia & -0.099 & 0.037 & $-0.154 * *$ & $-0.174^{* *}$ \\
\hline & $(0.057)$ & $(0.058)$ & $(0.058)$ & $(0.061)$ \\
\hline Slovakia & -0.020 & -0.095 & $-0.401 * *$ & 0.027 \\
\hline & $(0.059)$ & $(0.062)$ & $(0.063)$ & $(0.061)$ \\
\hline Constant & $-1.273^{* *}$ & $-0.970 * *$ & $-1.161 * *$ & $-1.507^{* *}$ \\
\hline & $(0.163)$ & $(0.168)$ & $(0.172)$ & $(0.174)$ \\
\hline Observations & 24354 & 24354 & 24354 & 24354 \\
\hline Log-Likelihood & -11786.14 & -10756.74 & -10524.24 & -10611.38 \\
\hline Log-Likelihood at zero & -12271.16 & -11215.79 & -11163.99 & -10993.87 \\
\hline
\end{tabular}




\section{References}

Alkire, S. and Foster, J. (2011), "Counting and Multidimensional Poverty Measurement," Journal of Public Economics, forthcoming.

Benjamin, D., Heffetz, O., Kimball, M. and Rees-Jones, A. (2010). "Do People Seek to Maximize Happiness? Evidence from New Surveys", Cornell University, mimeo.

Bossert, W, Chakravarty, S.R. and D'Ambrosio, C. (2009) "Multidimensional poverty and material deprivation," ECINEQ WP 129.

Bourguignon, F. and Chakravarty, S.R. (2003), "The Measurement of Multidimensional Poverty". Journal of Economic Inequality, 1, 25-49.

Clark, A.E., and Senik, C. (2010). "Who compares to whom? The anatomy of income comparisons in Europe". Economic Journal, 120, 573-594

Clark, A.E., Frijters, P., and Shields, M. (2008). "Relative Income, Happiness and Utility: An Explanation for the Easterlin Paradox and Other Puzzles". Journal of Economic Literature, 46, 95-144.

Decancq, K., Fleurbaey, M. and Schokkaert, E. (2009). " What Good is Happiness?", ECORE Discussion Paper No. 2009/38.

Deci, E., and Ryan, R. (2000). "The "what" and "why" of goal pursuits: Human needs and the self-determination of behaviour". Psychological Inquiry, 11, 227-268.

Deci, E., and Ryan, R. (2008). " Hedonia, eudaimonia, and well-being: an introduction". Journal of Happiness Studies, 9, 1-11.

Diener, E., and Seligman, M. (2004). "Beyond Money. Toward an Economy of Well-Being". Psychological Science in the Public Interest, 5, 1-31.

Fleurbaey, M. (2009). "Beyond GDP: The Quest for a Measure of Social Welfare". Journal of Economic Literature, 47, 1029-75.

Huppert, F. and So, T. (2009), "What percentage of people in Europe are flourishing and what characterises them?", Well-Being Institute, University of Cambridge, mimeo. 
Huppert, H., Marks, N., Clark, A.E., Siegrist, J., Stutzer, A., Vittersø, J., and Wahrdorf, M. (2009). "Measuring well-being across Europe: Description of the ESS Well-being Module and preliminary findings". Social Indicators Research, 91, 301-315.

Krueger, A., and Schkade, D. (2008). "The Reliability of Subjective Well-Being Measures". Journal of Public Economics, 92, 1833-45.

Loewenstein, G. and Ubel, P. (2008). "Pain and Suffering Awards: They Shouldn't Be (Just) about Pain and Suffering”, Journal of Legal Studies, 37, S195-S216.

New Economics Foundation (2008), National Accounts of Well-being: bringing real wealth onto the balance sheet. www.nationalaccountsofwellbeing.org.

Nolen-Hoeksema, S. and Rusting, C.L. (1999). "Gender differences in well-being". In D. Kahneman, E. Diener, \& N. Schwarz (Eds.), Well-being: The foundations of hedonic psychology. New York: Russell Sage Foundation.

Oswald, A. and Wu, S. (2010). "Objective Confirmation of Subjective Measures of Human Well-being: Evidence from the USA", Science, 327, 576-579.

Ryff, C. (1989). "Happiness is everything, or is it? Explorations on the meaning of psychological well-being". Journal of Personality and Social Psychology, 57, 10691081 .

Ryff, C., and Singer, B. (1998). "The contours of positive human health". Psychological Inquiry, 9, 1-28.

Senik, C. (2010). " Peut-on dire que les Français sont malheureux ?". In P. Askenazy \& D. Cohen (Eds.), Nouvelles Questions D'Economie Contermporaine. Economiques 2. Paris: Albin Michel.

White, M., and Dolan, P. (2009). "Accounting for the Richness of Daily Activities". Psychological Science, 20, 1000-1008. 